\title{
Alternative translation initiation codons for the plastid maturase MatK: unraveling the pseudogene misconception in the Orchidaceae
}

\author{
Michelle M. Barthet ${ }^{1,2^{*}}$, Keenan Moukarzel ${ }^{3}$, Kayla N. Smith', Jaimin Patel ${ }^{3}$ and Khidir W. Hilu ${ }^{3}$
}

\begin{abstract}
Background: The plastid maturase MatK has been implicated as a possible model for the evolutionary "missing link" between prokaryotic and eukaryotic splicing machinery. This evolutionary implication has sparked investigations concerning the function of this unusual maturase. Intron targets of MatK activity suggest that this is an essential enzyme for plastid function. The matK gene, however, is described as a pseudogene in many photosynthetic orchid species due to presence of premature stop codons in translations, and its high rate of nucleotide and amino acid substitution.
\end{abstract}

Results: Sequence analysis of the matK gene from orchids identified an out-of-frame alternative AUG initiation codon upstream from the consensus initiation codon used for translation in other angiosperms. We demonstrate translation from the alternative initiation codon generates a conserved MatK reading frame. We confirm that MatK protein is expressed and functions in sample orchids currently described as having a matK pseudogene using immunodetection and reverse-transcription methods. We demonstrate using phylogenetic analysis that this alternative initiation codon emerged de novo within the Orchidaceae, with several reversal events at the basal lineage and deep in orchid history.

Conclusion: These findings suggest a novel evolutionary shift for expression of matK in the Orchidaceae and support the function of MatK as a group II intron maturase in the plastid genome of land plants including the orchids.

Keywords: MatK, Orchidaceae, Monocots, Pseudogene, Chloroplast, Alternative initiation codons

\section{Background}

Maturases are enzymes that splice introns from precursor RNAs. They are most commonly found in prokaryotes and are thought to be the evolutionary splicing ancestor of the eukaryotic splicesome $[1,2]$. Maturases have three functional domains: a reverse transcriptase domain, a DNA endonuclease domain and a maturase (RNA binding and splicing) domain, referred to as domain $\mathrm{X}[1,3]$. Unlike the splicesome, each maturase usually removes only a single target intron [1, 2, 4]. To date, a total of six maturases have been identified in eukaryotic plant cells: four nuclear-encoded, one mitochondrial-encoded $[1,5]$

\footnotetext{
*Correspondence: mbarthet@coastal.edu

'Department of Biology, Coastal Carolina University, Conway, SC 29526, USA

${ }^{2}$ School of Biological Sciences, University of Sydney, Sydney, NSW 2006,

Australia

Full list of author information is available at the end of the article
}

and one, matK, plastid-encoded [6, 7]. Among these, MatK, the protein product of the matK gene, stands out as having the ability to splice up to seven target introns [2], implicating an evolutionary divergence from its prokaryotic relatives to a role more similar to that of the eukaryotic nuclear splicesome.

The $m a t K$ gene is encoded within the group IIA intron of $\operatorname{trn} K^{(\mathrm{UUU})}$ in most land plants and some green algae $[6,8]$. In a few plant species, the surrounding $\operatorname{trn} K^{\text {(UUU) }}$ exons were lost but $m a t K$ was retained as a freestanding gene in the plastid genome. Examples include the fern Adiantum capillus-veneris [9], parasitic angiosperms such as the beech-drops Epifagus virginiana and some species of the dodder genus Cuscuta $[10,11]$. There are a few instances, principally in members of Cuscuta subgenus Grammica, in which the matK gene has been lost from the plastid genome [11]. In plants 
that have lost the matK gene, the group IIA introns, the principle targets for MatK protein activity, were also lost, suggesting co-evolutionary reduction and supporting the proposed function of MatK as a group IIA intron maturase of the plastid [11].

The proposed function of MatK as a group II intron maturase has gained substantial support through molecular studies that demonstrated expression across a wide range of angiosperms, identified intron targets and generated fine mapping of binding sites [2, 12, 13]. No knock-outs exist for the matK gene; however, studies of the ribosomal white barley mutant albostrians correlated lack of processing of MatK intron targets with lack of MatK protein [14-18]. Intron targets for MatK activity include introns within transcripts for four tRNAs ( $t R N A$ $V^{(U A C)}, t R N A I^{(G A U)}, t R N A A^{(U G C)}$, and $\left.t R N A K^{(U U U)}\right)$, two ribosomal proteins ( $r p l 2$ and rps12), and a subunit of chloroplast ATPase $(a t p F)$ [2]. All but one of these intron targets lie within RNAs essential for proper formation and function of the plastid translation complex, suggesting that MatK is a vital component of overall plastid activity. The atpf intron target implicates an important role for MatK in photosynthetic activity. It is curious, therefore, that numerous photosynthetic plant species of the second largest angiosperm family, the orchid family (Orchidaceae, monocots) [19] are noted to contain $m a t K$ as a pseudogene [20-23].

To date, there are over 121,000 entries of $m a t K$ gene sequence in GenBank. Of these, 3,094 have matK listed as a pseudogene, with approximately $82 \%(2,523)$ of these entries in the Orchidaceae. A pseudogene is a gene that lacks functional protein product $[24,25]$. Causes of transition to a pseudogene state include frame shifts leading to premature stop codons and subsequent truncated non-functional protein, decay of coding sequence due to high rate of nonsynonymous substitution, and loss of transcription or processing required for protein translation (reviewed in Harrison et al. [24]). Classification of mat $K$ as a pseudogene in the Orchidaceae has been based on the presence of frame-shift mutations, specifically non-triplet indels (insertions/deletions), resulting in apparent premature stop codons that form truncated protein $[20,22,23,26]$, as well as a high rate of nonsynonymous substitution [22].

The $m a t K$ gene is considered a rapidly-evolving gene due to a high rate of substitutions at both the nucleotide and amino acid level [21, 27-30]. Substitutions in matK are not concentrated in the third codon position but appear to be distributed almost equally among all three codon positions, resulting in a significantly higher nonsynomous substitution rate compared to other plastid genes $[29,30]$. This inherent mode and tempo of evolution renders matK as an invaluable gene in phylogenetic reconstruction and DNA barcoding $[29,31-35]$ despite the lingering assumptions of it potentially being a pseudogene.
In light of the importance of MatK in plastid function and its wide use in molecular phylogenetics and barcoding, it is important to examine the pseudogene designation of $m a t K$ in the Orchidaceae. Previous bioinformatic analysis has shown that the amino acid substitutions in MatK across land plants are not random but constrained to maintain the chemical nature and presumed function of MatK [36]. Thus, we focused in this study on the putative frame shift mutations that result in possible truncated protein. We examined 115 matK sequences from across the Orchidaceae for plausible alternative initiation codons and assessed their impact on the deduced amino acid sequences. Further, we examined MatK expression and activity in selected orchid species where it was noted as a pseudogene. We also assessed the pattern of initiation codon evolution in the Orchidaceae. We propose that the matK open reading frame (ORF) of the pseudogene-labelled GenBank entries in Orchidaceae represent cases where the gene has undergone evolutionary shifts resulting in a potential alternative out-offrame initiation codon. Translation from this alternative initiation codon alleviates previously described frame shift mutations $[20,22,23,26]$ and restores the ORF.

\section{Results}

\section{Alignments}

Two data sets were generated, one for the molecular and the other for the informatics aspects of this study. In the former case, GenBank nucleotide sequences were obtained for 13 orchid and four related monocot species representing cases where $m a t K$ was considered as either functional or a pseudogene (Table 1). Translation of matK sequence from the initiation codon used for other monocots (referred to hereafter as the consensus initiation codon, cic) produced full length amino acid sequence for MatK protein from the monocot species Asparagus aethiopicus, Hordeum vulgare, Saccharum officinarum, and Oryza sativa, and three orchid species (Fig. 1). Amino acid sequence from the remaining ten orchid species when translated from the cic displayed premature stop codons suggestive of truncated, non-functional protein (Fig. 1b). Two additional initiation codons were identified upstream of the cic. The first one located $-6 \mathrm{bp}$ upstream and in-frame with the cic, was found only in six of the thirteen orchid taxa examined in this data set (Fig. 2). The second upstream initiation codon was found ten bases upstream ( -10 position) but out-of-frame from the cic. This second alternative initation codon (aic) was identified in the mat $K$ gene sequence for all 13 orchid taxa examined and is the result of a four base insertion (ATGT) not found in the non-orchid monocots we examined (Fig. 2a, indel 1). Translation using the alternative initiation codon produced a full-length MatK reading frame for eight of the ten orchid taxa previously reported to 
Table 1 Accessions used for alignments in Figs. 1 and 2. Designation of matK functionality in GenBank and species taxonomic affiliation are noted

\begin{tabular}{llll}
\hline Family & Species & Accession & Designation \\
\hline Asparagaceae & Asparagus aethiopicus & [GenBank: AB646503] & functional \\
Poaceae & Hordeum vulgare & [GenBank: FJ897855] & functional \\
Poaceae & Saccharum officinarum & [GenBank: EU434295] & functional \\
Poaceae & Oryza sativa & [GenBank: AF148650] & functional \\
Orchidaceae & Neuwiedia borneensis & [GenBank: AY557209] & functional \\
Orchidaceae & Palmorchis trilobulata & [GenBank: AJ310052] & pseudogene \\
Orchidaceae & Maxillaria buchtienii & [GenBank: DQ210789] & pseudogene \\
Orchidaceae & Anthosiphon roseans & [GenBank: DQ210903] & pseudogene \\
Orchidaceae & Phaius tancarvilleae & [GenBank: KF673844] & functional \\
Orchidaceae & Govenia sp. & [GenBank: EF525690] & functional \\
Orchidaceae & Oreorchis sp. & [GenBank: EU266420] & pseudogene \\
Orchidaceae & Cremastra appendiculata & [GenBank: EU266421] & pseudogene \\
Orchidaceae & Cryptostylis erecta & [GenBank: AJ310014] & pseudogene \\
Orchidaceae & Caladenia catenata & [GenBank: AJ309997] & pseudogene \\
Orchidaceae & Spiranthes sinensis & [GenBank: HE575508] & pseudogene \\
Orchidaceae & Spiranthes vernalis & [GenBank: AJ310074] & pseudogene \\
Orchidaceae & Spiranthes cernua & [GenBank: AJ543917] & pseudogene \\
\hline & & &
\end{tabular}

contain premature stop codons when translated with the cic (Fig. 2b). A single questionable stop codon was found in MatK of Anthosiphon roseans (amino acid position 188) and Caladenia catenata (amino acid position 345 ) when translated using the aic. It is to be noted that the cic and the aic in Anthosiphon roseans are in the same frame (Fig. 2a).

In a broader assessment, we examined matK sequences of an additional 104 Orchidaceae species and seven monocot outgroup species; 91 of the orchids required translation from the aic whereas the remaining 13 and all outgroup species could be fully translated with the cic (Additional file 1: Table S1). All orchid species with sequence data extending beyond the conserved initiation codon examined in this study were found to contain both the aic and the cic in the 5 region of matK with the exception of a single taxon, Neottia nidus-avis (Additional file 2: Figure S1). Neottia nidus-avis [GenBank: EF079303.1] was a rare exception in the orchids and does not contain the cic or the aic unless RNA editing corrects one of these initiation codons in the transcript. Instead Neottia nidus-avis appears to use an initiation codon located -6 bp upstream and in-frame with the cic. The orchid species that utilize the aic display three pertinent indels that allow translation of potential fulllength matK ORF from this otherwise out-of-frame initiation codon. These indels include the four nucleotide insertion containing the aic (Fig. 2a, indel 1), a four base insertion +37 from the aic (Fig. 2a, indel 4) and a single base insertion +42 from the aic (Fig. 2a, indel 6). Together, these three indels represent insertions of a total of nine base pairs, a triplet, realigning the MatK reading frame to that used in non-orchid monocots and only distorting the reading frame for the region between the first and last indel (Fig. 2a, indel 1 and indel 6, respectively). This distortion results in a total of eleven amino acid changes near the $\mathrm{N}$ terminus of MatK when translated using the aic versus the cic in the Orchidaceae (Fig. 2b).

Other indels of importance include two single base pair insertions for taxa that maintain matK translation using the cic. Palmorchis trilobulata contains a single base insertion +18 from the cic, which is corrected by single base deletion at +31 (Fig. 2a, indels 3 and 5). Reverse situation of single base deletion/ insertion events are detected at the same positions in Maxillaria buchtienii that correct the ORF (Fig. 2a, indels 3 and 5).

\section{Ribosome Binding Site Analysis}

Transcription of the matK gene utilizes a promoter that most likely includes at least part, if not all, of the 5' trnK exon that lies close to $1000 \mathrm{bp}$ upstream of the matK ORF $[12,13]$. The transcript for this gene region would include, therefore, both the alternative and the consensus initiation codons. As such, promoter position would have no influence on which initiation codon was used for translation and, thus, it was not examined in this study.

Aligned sequences of 13 orchids and four non-orchid monocot species were examined for sequence elements suggestive of conserved ribosome binding sites in order to delineate which initiation codon (alternative or consensus) may be preferred for translation of MatK. A region with 


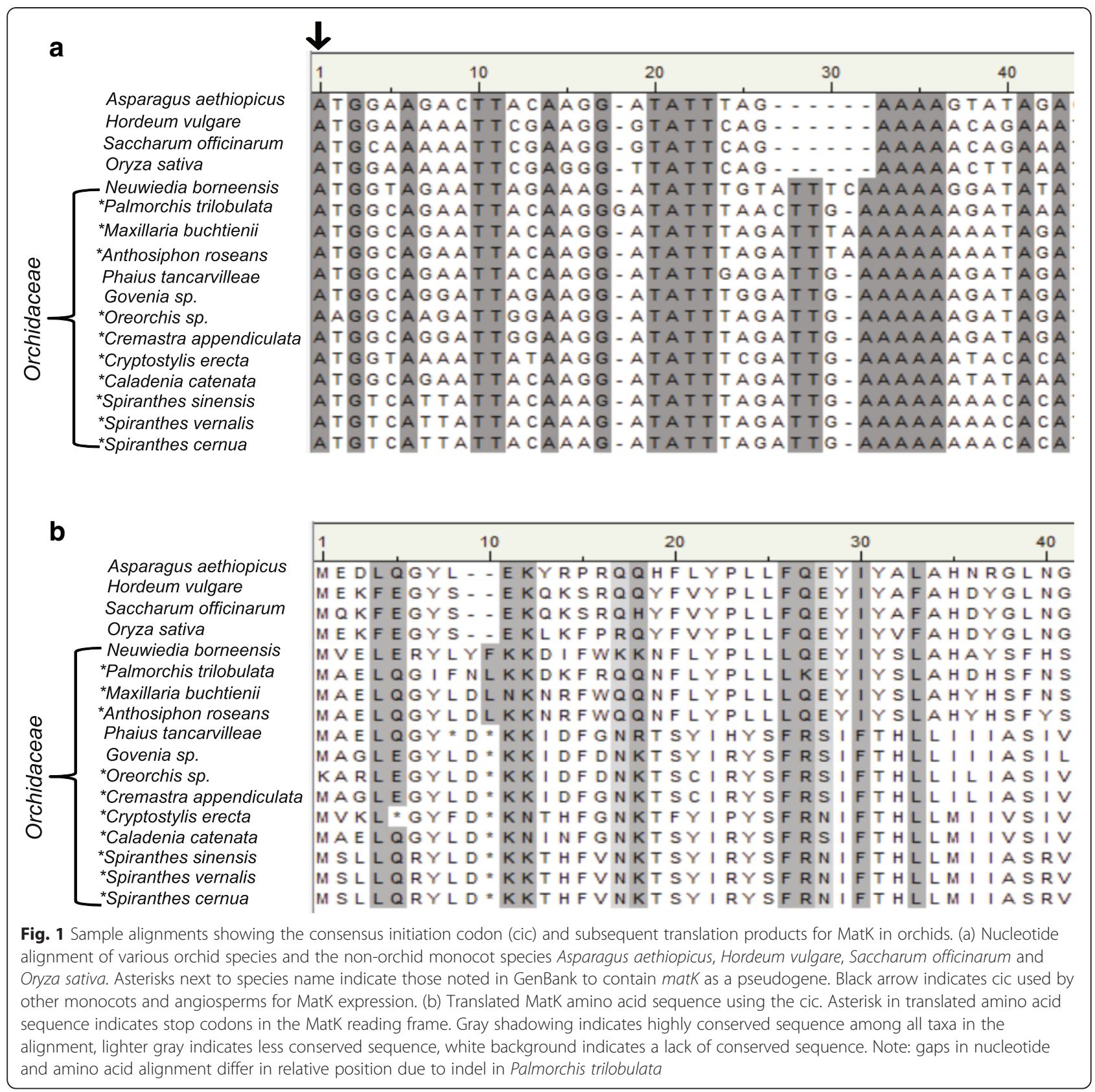

moderate sequence similarity to the Shine-Dalgarno (SD) consensus sequence (GGAGG) used for translation of some chloroplast mRNAs [37] was identified -31 to -28 bases upstream of the alternative AUG in Phaius tancarvilleae, Govenia sp., Cryptostylis erecta, Caladenia catenata, Spiranthes sinensis, $S$. vernalis, and $S$. cernua (Fig. 3). No other SD-like sequences were identified in closer proximity to either initiation codon for outgroup monocots or orchids. Other sequence features previously determined to affect translation in chloroplast mRNAs include the -1 triplet [38]. The -1 triplet surrounding the aic varied from AAA to GAA, whereas it varied from $\mathrm{C}$ / TAA to TCA for the cic (Fig. 3).

\section{Protein Expression and Function}

Protein expression of MatK was examined in five orchid species noted to contain matK as a pseudogene: Caladenia catenata, Cryptostylis erecta, Spiranthes vernalis [39], S. cernua [40] and S. sinensis [41]. This designation is due to the emergence of a premature stop codon in translations from the cic (Fig.1b). When translation was based on the aic, a full-length MatK reading frame was 


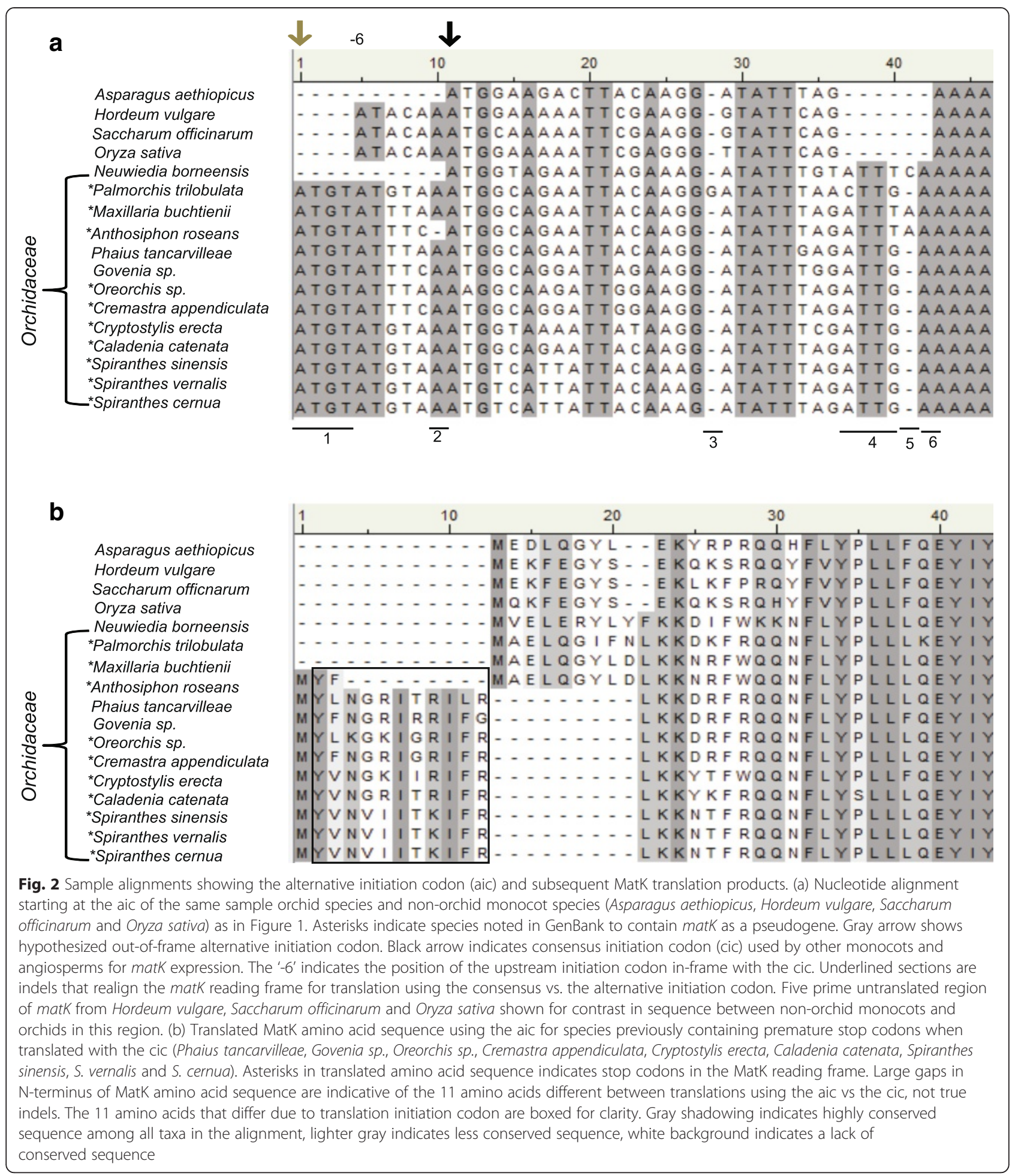

evident for these same species with the exception of $C$. catenata which is addressed later (Fig. 2a and b). In addition to these five species, we also examined MatK expression in the orchid Phaius tancarvilleae. The matK gene is noted as a pseudogene in one accession [GenBank: EF079306] but as a functional gene in a different accession [GenBank: KF673844] requiring the aic for full-length translation in the latter accession (Fig. $2 \mathrm{a}$ and b). An immune-reactive band ranging from 55 to $65 \mathrm{kDa}$ in mass was observed from Western blots of resolved total protein using an anti-MatK antibody [12] from all six orchid species (Fig. 4a and b). The expected 


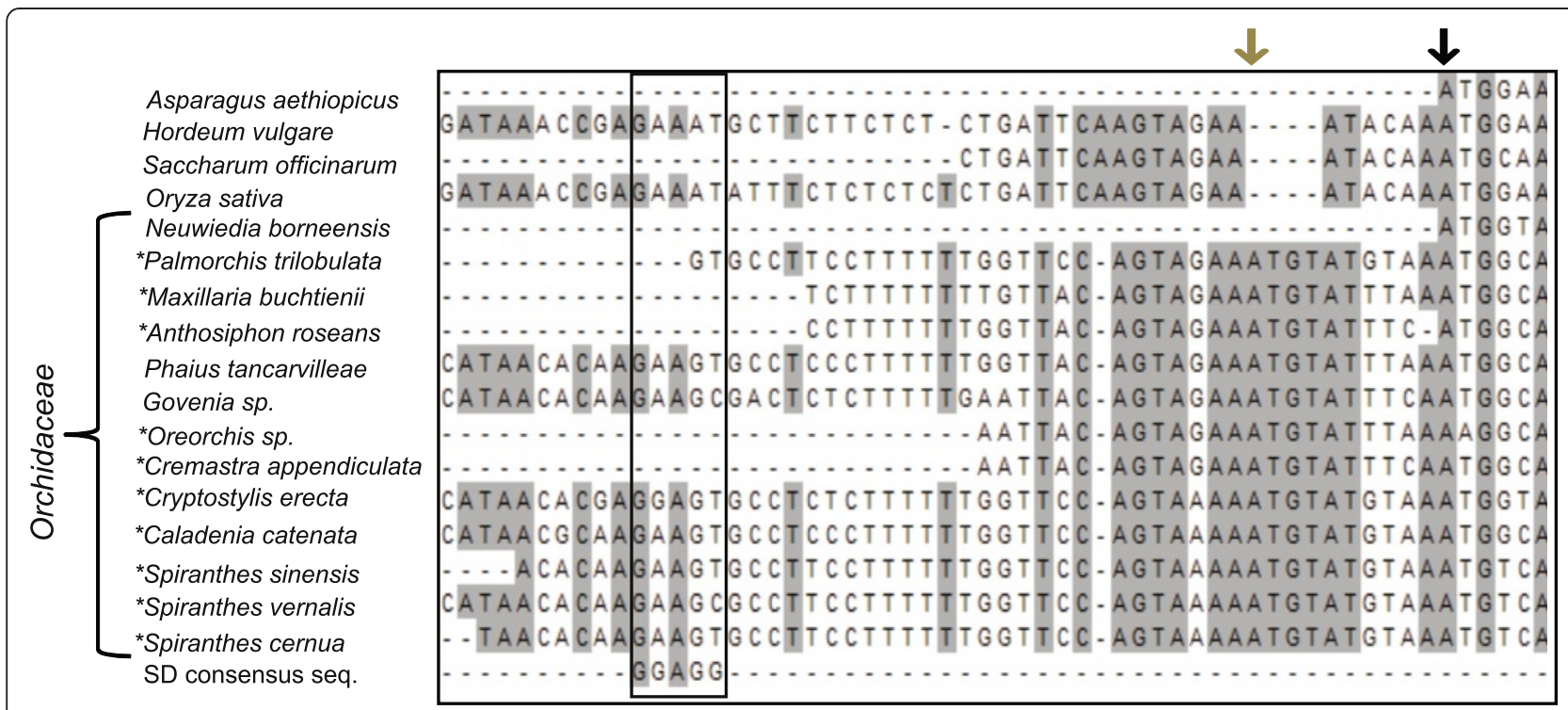

Fig. 3 Alignment of 5'UTR matK sequence to determine possible Shine-Dalgarno (SD) elements for ribosome binding. Asterisk indicates species noted in GenBank to contain matK as a pseudogene. Gray arrow shows hypothesized alternative out-of-frame initiation codon. Black arrow indicates consensus initiation codon used by other monocots and angiosperms for matK expression. SD-like region is boxed. SD consensus sequence is shown at bottom of alignment. Gray shadowing indicates highly conserved sequence among all taxa in the alignment, white background indicates a lack of conserved sequence

molecular mass of MatK from these orchid taxa is approximately $62 \mathrm{kDa}$ based on amino acid sequence.

Review of Ponceau S staining of $\mathrm{RbcS}$ and epitope alignment (Fig. 4a, b and c) demonstrated that discrepancy in signal strength of MatK from Western blots was not attributable to variation in protein loading/transferring to blots or to differences in sequence similarity of the epitope target of anti-MatK. Further there was no evidence of difference in protein degradation on the blots as the reason for the difference in signal strength (Fig. 4a and b). Rather, variation in signal strength may be ascribed to leaf developmental stage at time of collection. MatK has previously been shown to have higher expression during early verses later developmental stages $[12,13]$. Tissue samples used for protein analysis were collected from plants obtained through botanical gardens or distributors at various stages of development.

Pseudogenes are determined by the loss of their ability to make functional protein products [25]. As such, we assessed both the expression of MatK as well as its activity. We examined MatK activity in P. tancarvilleae, S. cernua, and S. vernalis. These orchid species were chosen based on tissue availability and as representatives of orchid species that require translation from the aic initiation codon (Fig. 2a and b). Reverse-transcriptase PCR (RTPCR) was used to amplify RNA targets of MatK maturase activity as an indirect indicator of MatK function. Recent analysis of MatK binding to intron substrates using RIPchip assays has identified the intron within $\operatorname{trnK} K^{(\mathrm{UUU})}$ as a primary target for MatK maturase activity [2]. Primers were designed to bind to $\operatorname{trnK} 5^{\prime}$ and 3 ' exons (Fig. 5a). Mature trnK product (intron removed) based on primer design, would result in a band slightly larger than 50 base pairs (bp) while precursor RNA still containing intron would result in a band of $\sim 2800 \mathrm{bp}$. Actual trnK product sizes in the orchids based on alignments ranged from 50 to $61 \mathrm{bp}$ depending on species. RT-PCR products of a little greater than 50 bp were evident after gel electrophoresis for all three orchid species examined (Fig. 5b). PCR products were sequenced and confirmed as the mature product of $t r n K^{(\mathrm{UUU})}$. Two additional PCR products of $\sim 2500$ and $\sim 3000$ bp were observed from PCR amplification of P. tancarvilleae cDNA (Fig. 5b). These same two products also were observed after PCR amplification of cDNA from some biological replicates of $S$. cernua (data not shown). These larger PCR products are consistent with transcript sizes for the unspliced $\operatorname{trn} K /$ matK gene region based on Northern blots $[12,13]$.

\section{Phylogenetic Impact of the Alternative Initiation Codon}

Phylogenetic trees derived from two data sets of the matK ORF, one aligned using the aic and the second aligned using the cic, are highly congruent with each other. Both phylogenetic trees depict the Apostasioideae being sister to remaining orchids, followed by the Vanilloideae, Cypripedioideae and a clade of Orchidoideae plus Epidendroideae. We opted to use the tree based on the aic for presenting the results and discussing the pattern of matK initiation codon evolution. A summary tree is presented in Fig. 6, whereas the detailed tree is 


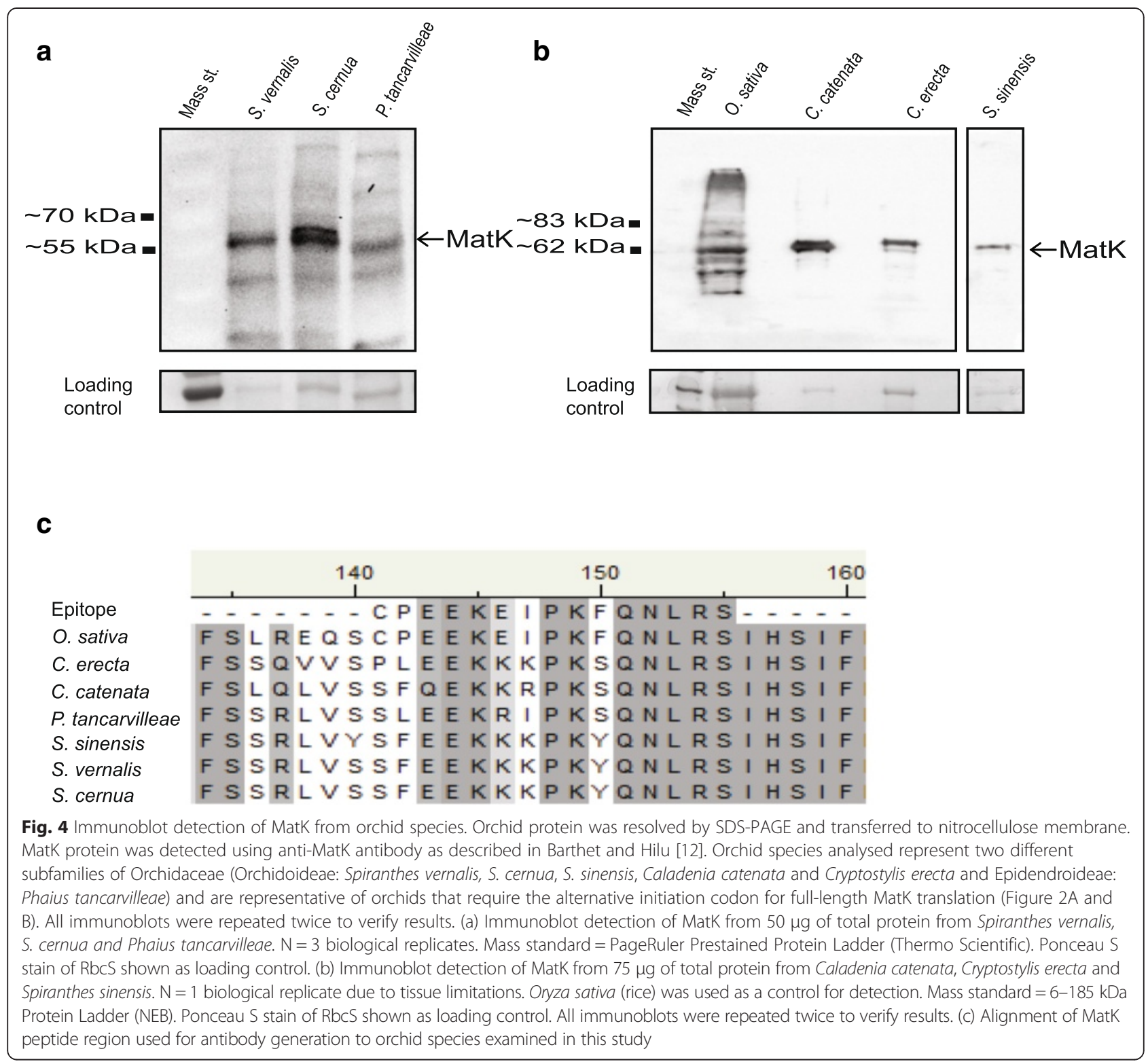

presented in Additional file 3: Figure S2. A full matK reading frame in all outgroup taxa is obtained based on the cic. Members of the Apostasioideae, the most basal lineage in the Orchidaceae, show full-length MatK translation based on the consensus but not the alternative initiation codon. The exception is Apostasia nuda [GenBank: AY557214] that appears to use the aic. In the subsequent diverging lineages, Vanilloideae and Cypripedioideae, all GenBank accessions require the aic for MatK translation. Insertions leading to reversal events to the cic for MatK translation re-emerged later in two orchids subfamilies Epidendroideae (tribes Neottieae, Cymbidieae and Epidendreae), and Orchidoideae (tribe Diurideae) (Figure 6, Additional file 1: Table S1).

\section{Discussion}

Over 3000 GenBank entries across the five Orchidaceae subfamilies have matK labelled as a pseudogene with some notable inconsistencies in designation. For instance, two accessions of Spiranthes sinensis [GenBank: AB040206 and JF972946] describe matK as a functional gene and provide full-length translated amino acid sequence while one accession [GenBank: HE575508] lists $m a t K$ as a pseudogene with no translation. We assessed nucleotide sequence data for over 115 orchid taxa representing all the subfamilies to determine plausible explanations for the perceived pseudogene notations of matK in this family. The underlying reason for labelling mat $K$ as a pseudogene vs. functional gene is the choice of 


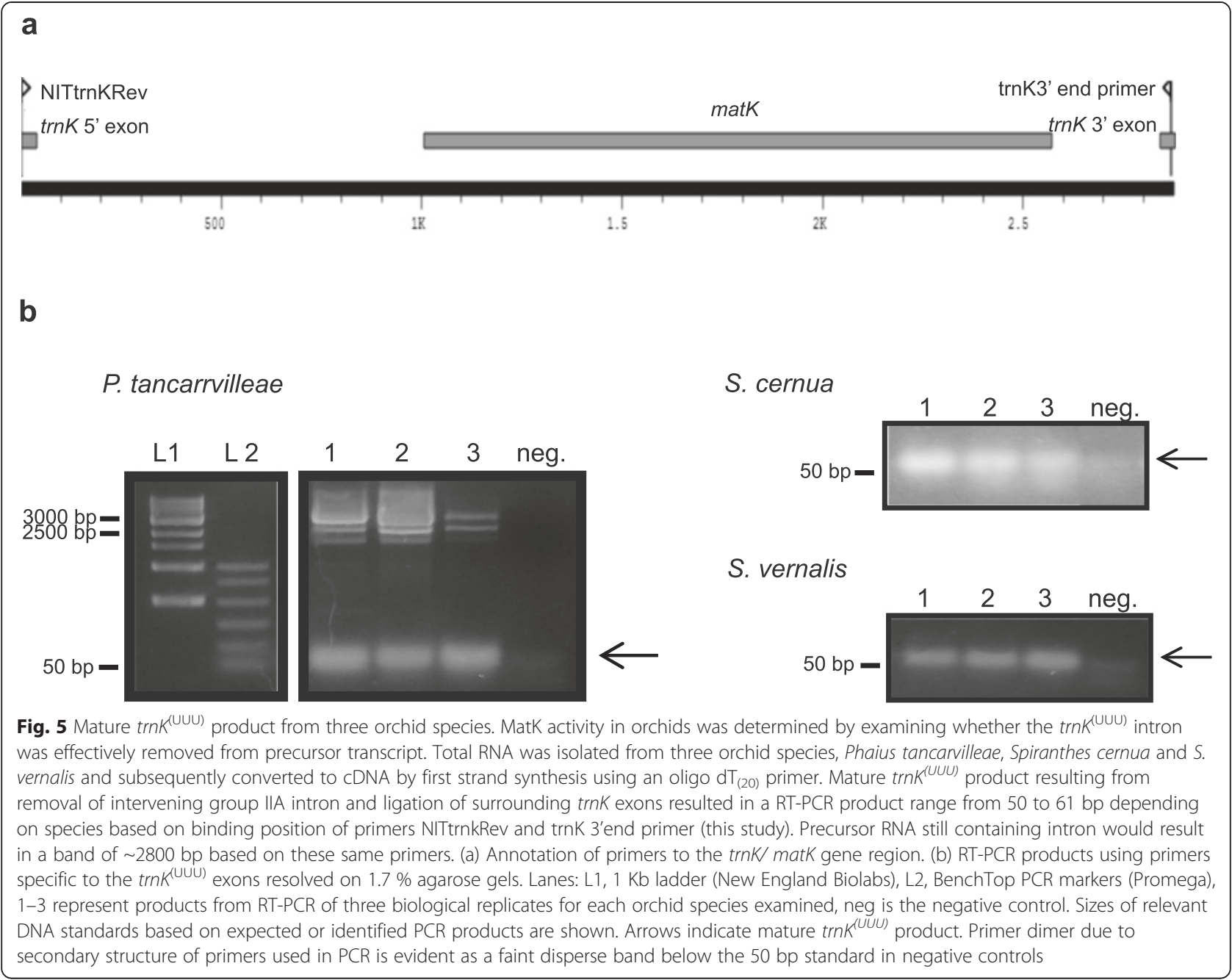

AUG initiation codon used for translation, as protein translation is highly dependent on the frame used. In the accessions where matK was labelled as "pseudogene", we identified an alternative AUG (ATG shown in our DNA alignments) initiation codon ten nucleotides upstream and out-of-frame from the initiation codon used for matK translation in other monocots (Fig. 2a). This alternative initiation codon has been overlooked, or possibly avoided since it is out-of-frame with the cic traditionally used in matK translation, resulting in inconsistencies of functionality designation. One such example is with the aforementioned Spiranthes sinensis [GenBank: HE575508] which lists $m a t K$ as a pseudogene. Although this accession lists $m a t K$ as a pseudogene, the ORF can be translated fully from the alternative initiation codon located at position 37-39 of the submitted sequence (Fig. 2b). Our investigation has demonstrated that the misidentification of the correct initiation codon has led to the predominant labelling of $m a t K$ as a pseudogene in the Orchidaceae and the consequent inaccurate conclusions about matK molecular evolution in the family. For example, it has been suggested that mat $K$ is transitioning towards a pseudogene state in the orchid subfamily Apostasioideae due to translation using the cic [42]. However, MatK can be translated into a full-length amino acid sequence for all members of this subfamily from sequences available in GenBank using either the cic or the aic depending on species (Additional file 1: Table S1).

\section{Molecular Analysis of MatK Expression in the Orchidaceae} The use of multiple initiation codons, including out-offrame initiation codons has been previously identified for plant viral mRNAs [43]. In general, translation initiates at the 5' proximal AUG; however flanking sequence features influence initiation codon choice [44]. These sequence features differ between eukaryotic and prokaryotic mRNA. Eukaryotic mRNAs tend to contain a Kozak sequence to signal the primary AUG for translation initiation while prokaryotic mRNAs contain the ShineDalgarno (SD) sequence. Many chloroplast mRNAs include an upstream SD-like sequence [37], reflecting their prokaryotic ancestry. Typically the SD sequence is 


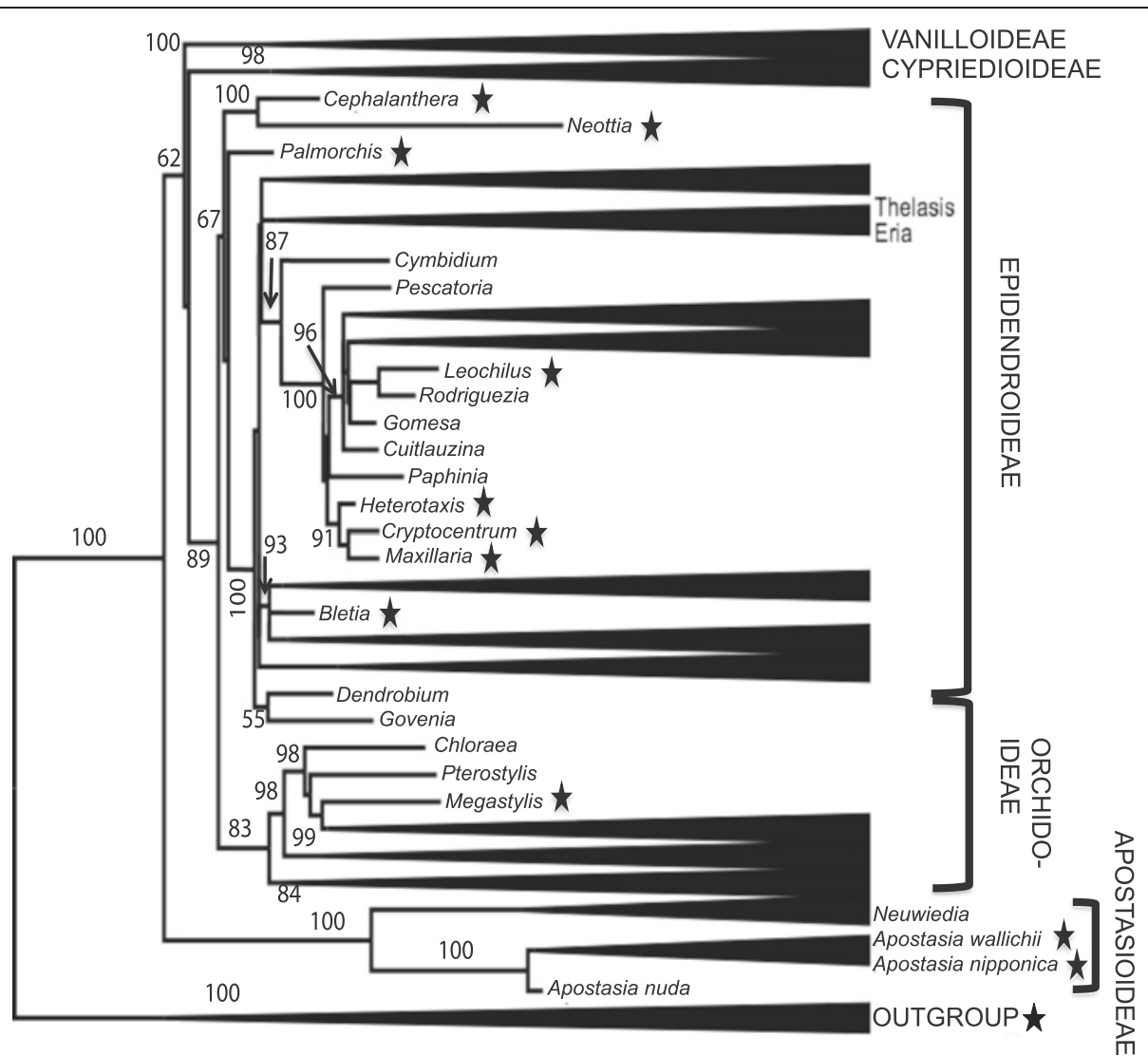

Fig. 6 Summarized phylogeny of Orchidaceae determined using matK nucleotide sequence alignment based on alternative initiation codon. The tree is rooted with members of the Asparagales monocot families Asteliaceae (Astelia alpina, Milligania stylosa), Blandfordiaceae (Blandfordia grandiflora), Boryaceae (Borya septentrionalis), Hypoxidaceae (Hypoxis hemerocallidea, Spiloxene serrate), and Lanariaceae (Lanaria lanata). Asterisks indicate evolutionary lineages that utilize the consensus initiation codon for MatK expression. Lineages lacking asterisks utilize the alternative initiation codon. Relationships were constructed using the maximum likelihood method RAxML in the CIPRES portal (http://www.phylo.org) [70] applying the default settings and conducting 1000 replicates. Bootstrap values are noted on the nodes

located approximately -10 bases upstream from the initiation AUG [37]. Examples include the plastid genes $r b c L$ and $a t p E$ which use a SD-like sequence highly similar to that from E. coli (GGAGG), and in relatively the same position from the initiation codon in E. coli translation ( -10 to -6 bases and -18 to -15 bases, respectively) [37]. Other plastid mRNAs, however, have been found to have SD-like sequences anywhere from -2 to -44 bases upstream from the initiation codon [37]. The relative position of the SD sequence in chloroplast mRNAs is an indicator of whether or not the SD sequence is used for ribosome binding. If the SD sequence is in very close proximately to the initiation codon (within a few bases) or much farther upstream, e.g. greater than -20 bases, the SD sequence may not influence ribosome binding and translation [37]. Other sequence features that tend to affect translation of chloroplast mRNAs include the sequence of the -1 triplet and the sequence of the initiation codon itself [38]. A SD-like region was identified upstream of the matK alternative initiation codon of orchids (Fig. 3). The distance from the putative $\mathrm{SD}$ region to the alternative initiation codon $(-32$ to -29 ) suggests that this region most likely does not influence translation. This same SD-like region in the non-orchid monocot taxa examined resides more than 35 bases upstream from the initiation codon (Fig. 3). It is likely, therefore, that the SD sequence has little influence on matK expression in monocots. These results are consistent with previous analysis of regulatory elements for matK expression [45]. Using heterologouslyexpressed MatK in E. coli, Zoschke et al. [45] demonstrated that SD-like sequences are not required for matK translation. The nucleotide triplet -1 from the initiation codon also has been found to influence translation efficiency for chloroplast mRNAs due to possible extended codon-anticodon interaction [38]. The most essential aspect of the -1 triplet is the nucleotide at the -1 position relative to the initiation codon, with uracil being the preferred nucleotide to enhance anticodon binding [38]. The -1 triplet varied from GAA or AAA -1 of the 
aic to C/TAA or TCA -1 of the cic in mat $K$ depending on species (Fig. 3). None of these triplets regardless of initiation codon included a uracil (thymine in our DNA alignments) at the -1 position. Thus, the -1 triplet offers little information for discerning matK initiation codon choice. We propose, therefore, that other unknown sequence features must influence initiation codon choice for matK.

Western blots were used to determine whether MatK is expressed in selected orchid species currently noted to contain $m a t K$ as a pseudogene (Table 1; [39-41]). The immune-detection of protein bands corresponding to full-length MatK protein support that MatK is expressed in these orchid species (Fig. 4a and b). As pseudogenes are also characterized by a lack of function [24], we examined the splicing of the trnK intron as an indirect indicator of MatK activity in three orchid species, two of which, Spiranthes cernua and S. vernalis, are suggested to contain matK as a pseudogene [40, 41]. Analysis of the trnK region by RT-PCR supports that the $\operatorname{trnK}$ intron is efficiently removed in both orchid species (Fig. 5b). As no inhibitors for MatK acitivity currently exist, direct in vivo assessment of MatK splicing is not currently possible. Studies of MatK-substrate binding by RIP-CHiP analysis [2] and the white barley mutant albostrains $[16,17]$ support that MatK is the most likely factor for splicing of the trnK (UUU) intron in this study. Thus, some mechanism must be in place in these members of the Orchidaceae to allow expression of fulllength functional MatK protein. Two possibilities exist to explain the expression of MatK from the orchids with matK pseudogene designation: 1) another copy of the $m a t K$ gene exists in the orchid genome which lacks premature stop codons or 2) expression occurs using the alternative out-of-frame initiation codon identified in this study (Fig. 2a). Twelve plastid genomes from members of the Orchidaceae have been completely sequenced: Dendrobium officinale [GenBank: NC_024019], Cymbidium aloifolium, Cymbidium manni, Cymbidium tracyanum, Cymbidium tortisepalum, Cymbidium sinense [46], Erycina pusilla [47], Neottia nidus-avis [26], Oncidium hybrid cultivar [48], Phalaenopsis aphrodite [49], Phalaenopsis equestris [50], and Rhizanthella gardneri [51]. None of these sequenced genomes account for a second copy of $m a t K$ in the plastid genome. Consequently, our data suggest that MatK expression occurs using the alternative out of frame initiation codon identified in this study.

There has been one report of a second copy of mat $K$ in the plastid genome in members of Corallorhiza (Orchidaceae) and closely related genera such as Oreorchis and Aplectrum [52]. In these genera, one copy of matK appears intact, while the other copy, the pseudogene copy, contains a deletion of $380 \mathrm{bp}$ at the 5 ' end along with several non-triplet indels leading to premature stop codons and truncated amino acid sequence [52]. Sequences of Cremastra appendiculata and Oreorchis sp., both of which are genera closely related to Corallorhiza, were analysed in this study and found to utilize the alternative initiation codon for translation of full-length MatK amino acid sequence (Fig. 2a and b). The sequences of C. appendiculata and Oreorchis sp. used in our assessment [GenBank: EU266421 and EU266420 respectively] lack large deletions in the 5' end of the mat $K$ gene and, therefore, are not the pseudogene copy of mat $K$ in the plastid genome described by Freudenstein et al. [52] but a second copy that contains the aic for translation. Thus, even for genera with a potential second copy of mat $K$, the aic appears to be the main initiation codon for translation of full-length MatK protein.

Western blot detection of a $62 \mathrm{kDa}$ anti-MatK immune reactive band from Caladenia catenata (Fig. 4b) presents an unusual case in which molecular and sequence data are in disagreement. The longest reading frame deduced from translation of the sole accession for this orchid species [GenBank: AJ309997] is only 344 amino acids long, generated using the upstream aic (Fig. $2 \mathrm{a}$ and b). This translation is approximately 160 amino acids shorter than normal matK ORF. Translation from the aic of Petalochilus catenatus (a synonym for the same species) [GenBank: GQ866570] results in a full-length MatK reading frame. Sequence identity between $P$. catenatus and $C$. catenata is $\sim 100 \%$, differing in a nucleotide at position +932 which is missing in C. catenata relative to P. catenetus. Correcting this discrepancy in $C$. catenata eliminates all the premature stop codons, resulting in a full ORF recovery when translated with the aic. The $m a t K$ gene is described as a pseudogene for C. catenata [GenBank: AJ309997] but as a functional gene for P. catenatus [GenBank: GQ866570]. Therefore, this case points to a possible sequence error and provides a convincing argument against the pseudogene labelling of mat $K$ in $C$. catenata.

A case similar to Caladenia catenata is notable in the matK sequence of Anthosiphon roseans. The single accession available for this species [GenBank: DQ210903.1] is labelled as pseudogene and displays both the aic and cic in frame with each other, separated by six nucleotides. Translation from either initiation codon revealed one premature stop codon (TAG) at +559 from the upstream aic. When the sequence is aligned with Maxillaria longipes [GenBank: DQ210999] of the same tribe, a mutation in this codon position from TTG to TAG is apparent. Sequence identity between these two species is $99 \%$, remarkably high for species belonging to two different genera. This degree of identity argues strongly against mat $K$ being a pseudogene in $A$. roseans as mutation rates in non-functional genes are exceedingly high due to relaxed selection pressure on them [53]. Thus, the premature stop codon here is either a sequencing error or 
possibly is subjected to RNA editing. RNA editing has been previously observed in the matK transcript from various plant species including the orchids with up to three reported editing sites [16, 54-57].

Phaius tancarvilleae presents an unusual case of sequencing differences in GenBank. There are a total of nine accessions for mat $K$ in $P$. tancarvilleae (Additional file 4: Figure S3). One accession [GenBank: EU490700] is partial, missing part of the 5 upstream region thus preventing determination of the initiation codon. Two accessions [GenBank: AB040205, EF079306] suggest full-length translation of $m a t K$ using the cic, while all remaining accessions require the aic for full-length MatK expression (Additional file 4: Figure S3). The sequences of the three biological replicates of $P$. tancarvilleae used in this study [GenBank: KP204599, KP204600 and KP2046010] display100\% identity with that of [GenBank: KF852707], and require the aic for full-length matK translation. Thus, the inconsistency in initiation codon usage for $P$. tancarvilleae implies an apparent variation at the species level, but also could signify a case of sequencing error.

\section{Pattern of Evolution of the Alternative Initiation Codon}

In our extended data set of over 100 orchid species, 13 species were determined to require translation from the cic. To assess the pattern of emergence of the aic, we mapped the aic and cic on a phylogenetic tree derived from our data sets (Fig. 6). This tree is in agreement with the general consensus on the pattern of subfamily divergences in the Orchidaceae, depicting the subfamily Apostasioideae at the base, followed by the subfamilies Vanilloideae, and Cypripedioideae in a grade sister to an Orchidoideae plus Epidendroideae clade $[42,58,59])$. Except for Apostasia nuda, the Apostasioideae matK sequences display the cic as the appropriate one for translation. The use of the matK consensus initiation codon for translation in the first diverging subfamily Apostasioideae and in the closely related sister families, and the prevalence of the aic for MatK translation in the subsequently diverging subfamilies (Fig. 6) provides unequivocal evidence for the evolution of the alternative initiation codon within the orchids. The Apostasioideae includes two genera, Neuwiedia and Apostasia and a total of 16 species, 10 of them have matK sequence representation in GenBank. The Apostasioideae is an intriguing orchid group. Members of this subfamily differ morphologically from most remaining orchids in a number of features, including the lack of the column (gynostemium), a product of fusion of the stamens and the style, which is a prominent feature of the orchids, and the presence of powdery instead of sticky pollen [42, 60]. These traits render the subfamily Apostasioideae as an evolutionary link between the core Orchidaceae and the rest of the order Asparagales where the orchid family resides. Therefore, it fits that the matK in the Apostasioideae presents a transitional evolutionary stage from the consensus to the new alternative initiation codon for MatK translation. It is to be noted that $A$. nuda occupies a basal position in the Apostasia clade [42]; this study, pointing to an early reversal event from the alternative to the consensus initiation codon in the family.

Multiple reversal events to the cic also appear in the terminal lineages of the Orchidaceae, namely the subfamilies Epidendroideae and Orchidoideae (Fig. 6). It is rather striking that a reversal was first recovered in members of the tribe Neottieae, which emerged at the very base of the subfamily Epidendroideae in our phylogenetic analyses, a position corroborated by the work of Burns-Balogh and Funk [61], Xiang et al. [62] and Freudenstein et al. [63]. All three genera of this tribe (Cephalanthera, Neottia and Palmorchis) require the cic for full ORF translation (Fig. 6, Additional file 1: Table S1). Subsequent lineages in the Epidendroideae reverted back to the aic for MatK translation, but other reversal events to the cic were detected deep in this subfamily in members of the tribe Maxillarieae and in Bletia of the tribe Epidendreae (Fig. 6, Additional file 1: Table S1). Therefore, the loss and gain of the consensus initiation codon for MatK translation in the Orchidaceae does not seem to be at random but is confined to specific lineages, e.g. subfamily Epidendroideae and one species in the subfamily Orchidoideae.

The underlying evolutionary drive for the emergence of the aic and the reversals to the cic in the Orchidaceae is not clear. It may reflect possible evolutionary structural/functional constraint on matK. More likely, the presence of an additional potential initiation codon is a buffering mechanism required to offset otherwise potential deleterious frequent losses/gains of nucleotides in matK. This latter hypothesis is based on the unusually high substitution rate in matK [21, 27-30] and the high variability of the N-terminus region of MatK protein in both length and amino acid composition [10, 36, 64]. Further support for this hypothesis is found in the minimal impact of the use of the aic verses the cic in MatK translations. Only 11 amino acids are altered in the $\mathrm{N}$ terminus with aic translations compared to cic translations due to subsequent restoration mutations (four base-pair insertions at +1 and +37 positions and the one base-pair insertion at +42 from the aic (Fig. 2a, indels 1 , 4 and 6 , and $2 b)$ ). The remarkably balanced substitution/indel molecular evolutionary pattern observed in the 5 ' region of matK, which maintains expression of intact MatK protein, supports the significance of this gene/protein in plastid/plant function. A similar mechanism is evident at the extreme 3' end of the gene where non-triplet indels have been observed. In these cases, 
alternate stop codons immediately downstream from the consensus stop codon are present and could be used to terminate translation and maintain ORF integrity [65], again emphasizing the importance of this gene and its protein product for plant function.

\section{Conclusions}

This study has uncovered a unique evolutionary event affecting the expression of matK, which is an essential splicing factor in the plastid and a well-utilized gene in plant molecular systematics. Designation of matK as a pseudogene has been primarily determined by nucleotide sequence translation starting at an initiation codon identified through alignment to other angiosperms. The mat $K$ gene in most members of the Orchidaceae has had an evolutionary divergence due to the insertion of four bases upstream from the 'normal' (consensus) initiation codon, identified in this study as the alternative initiation codon. Although this initiation codon is out-of-frame with the downstream initiation codon, translation from this upstream initiation codon results in a full-length MatK reading frame with high amino acid sequence identity to the amino acid sequence for MatK from all other angiosperms. In support of these points, we have demonstrated using Western blot and RT-PCR experiments that full-length MatK protein is expressed and functions in sample orchid species currently designated to contain $m a t K$ as a pseudogene. We believe in light of current evidence presented, designation of $m a t K$ as a pseudogene in the orchids needs to be reassessed to address the functional and phylogenetic consequences of this designation.

\section{Methods}

\section{matK Data Sets and Phylogenetic Analyses}

We examined 777 mat $K$ sequence entries of angiosperm from GenBank with a focus on monocots where the Orchidaceae resides. Among these, 104 Orchidaceae species have sufficient 5 ' sequence to determine initiation codon suitability. Species chosen for alignment represent all the five subfamilies currently recognized for the Orchidaceae $[58,60]$ with a broader sampling of species from the largest subfamily Epidendroideae. For tree rooting, seven species from five sister families to the Orchidaceae were used: Borya septentrionalis (Boryaceae), Blandfordia grandiflora (Blandfordiaceae), Milligania stylosa and Astelia alpina (Asteliaceae), Lanaria lanata (Lanariaceae), and Spiloxene serrate and Hypoxis hemerocallidea (Hypoxidaceae).

Nucleotide sequences for the matK ORF were aligned with QuickAlign [66] and translated into amino acids in MacClade [67]. The insertion of gaps in the sequence alignments took into consideration their cost in the homology assessment following Kelchner [68]. The presence of the aic enforced the insertion of gaps that are not in triplets in the region immediately downstream of the initiation codon. Two alignments were generated differing in whether the consensus or alternative initiation codon was used for translation. The data sets were analyzed phylogenetically using the Maximum Likelihood (RAxML version 8; [69] method in the CIPRES portal (http://www.phylo.org) [70] applying the default settings and conducting 1000 replicates. Bootstrap support was calculated for the $50 \%$ majority trees. FigTree v1.3.1 (http://tree.bio.ed.ac.uk/software/figtree/ ) [71] was used to prepare trees for publication.

Alignment of nucleotide and translated amino acid sequence for sample taxa in Figs. 1 and 2 was accomplished using Accelyrs Ds Visualizer software [72]. Accessions used for alignments in Figures 1 and 2 can be found in Table 1. Analysis of ribosome binding sites required the use of longer regions of the $\operatorname{trnK}$ (UUU) Lys intron and therefore, a different accession was used for P. tancarvilleae [GenBank: KP204599].

Accessions of Phaius tancarvilleae deposited in GenBank had significant discrepancies in nucleotide alignment with some accessions suggesting translation using the aic [GenBank: KF852707, KF673844, KF673843] and others the cic [GenBank: AB04205, EF079306] (Additional file 4: Figure S3). To delineate the correct sequence for this orchid species, genomic DNA from three biological replicates of $P$. tancarvilleae was extracted using the CTAB method [73]. A region from the trnK 5' exon to approximately $200 \mathrm{bp}$ in the matK CDS was amplified using primers BaseEUD200R and trnK3941 [74]. In order to obtain a longer sequence of the matK region, the entire CDS was amplified using primers phaiusmatKup5' (5'-CATAACACAAGAAGTGCCT-3') and trnK3'endprimer (5'GGGACTCGAACCCGGAA-3') (this study). Amplified products were cleaned using the QIAquick PCR Purification Kit (Qiagen) and sequenced. A non-flowering specimen of $P$. tancarvilleae was entered into the Coastal Carolina Herbarium under voucher number: CCUMMB0002.

\section{Source of Material for Molecular Assays.}

Orchid tissue used in this study was obtained through private vendors, botanic gardens or field collection (Additional file 5: Table S2). Confirmation of Spiranthes species collected from field was accomplished through sequencing of matK $\mathrm{cDNA}$ amplified after reverse transcription using the primers (SSFseq: 5'-TTC CATTCTCGTCGCGAT-3' and SSRseq: 5'-ACGAAGA AACCGAAATAG-3') (this study). These primers were designed to amplify a region of $369 \mathrm{bp}$ containing at least three mutations specific to individual species of Spiranthes. Alignment of sequence from all three biological replicates using Accelrys ${ }^{\odot}$ DS Visualizer [72] as well as BLAST search in GenBank confirmed field 
collection of S. vernalis. Prior to sequencing, residual components of the original PCR reaction were removed using QIAquick PCR Purification Kit (Qiagen). A flowering specimen of $S$. vernalis was entered into the Coastal Carolina Herbarium under voucher number: CCUMMB0001.

\section{Protein Extraction/ Western Blotting}

Approximately $200 \mathrm{mg}$ of frozen tissue was ground under liquid $\mathrm{N}_{2}$ and total protein extracted by addition of Laemmli SDS buffer (62.5 mM Tris, pH 6.8, 2 \% SDS, $10 \%$ glycerol and $5 \% \beta$-mercaptoethanol) with the addition of $1 \mathrm{mM}$ of phenylmethanesulfonyl fluoride (PMSF) protease inhibitor. Samples were subsequently boiled at $95{ }^{\circ} \mathrm{C}$ for 15 minutes and centrifuged twice at $15,000 \mathrm{X} \mathrm{g}$ for $10 \mathrm{~min}$. Protein concentration and qualitative immunodetection of MatK was accomplished as described by Barthet and Hilu [12]. In brief, protein concentration was determined by Bradford assay [75] and total protein resolved by SDS-PAGE followed by transfer to nitrocellulose membrane. Transfer and loading efficiency was determined by Ponceau S staining. Bound anti-MatK antibody [12] was detected using chemiluminescent detection with HRP-conjugated anti-rabbit IgG as the secondary antibody.

Orchids used for Western blot analysis included species from two different subfamilies (Orchidoideae: $S$. vernalis, S. cernua, S. sinensis, C. catenata, and C. erecta and Epidendroideae: P. tancarvilleae) and are representative of MatK protein requiring translation from the aic (Fig. 2a and b). Our choice of species was constrained by availability of orchid tissue from commercial vendors or botanic collections. Western blot experiments for P. tancarvilleae, S. vernalis and S. cernua were repeated using three biological replicates whereas a single biological replicate was used for $C$. erecta, $C$. catenata and $S$. sinensis. The last three orchid taxa, C. erecta, C. catenata and S. sinensis, are native to Australia with limited commercial or botanic availability outside of Australia limiting tissue availability for biological replicates. Oryza sativa protein extract was used as a positive control for antibody binding [12].

\section{RNA Extraction/ RT-PCR/ MatK Splicing Activity}

Leaf tissue was harvested from three biological replicates each of S. vernalis, S. cernua and P. tancarvilleae. Frozen tissue for each biological replicate was ground under liquid nitrogen and total RNA extracted using Qiagen Plant RNAeasy kit (Qiagen). Residual DNA was removed by DNA digest using Ambion's Turbo DNAse I (Ambion). First strand synthesis was accomplished using Superscript III First Strand Synthesis Kit (Invitrogen) and an oligo $\mathrm{dT}_{(20)}$ primer. Removal of DNA from RNA preparations was determined by PCR on RNA subjected to the first strand synthesis protocol lacking Superscript III reverse transcriptase (no-RT control). First strand cDNA was amplified using primers NITtrnkRev (5'- GG TTGCTAACTCAACGGTAGAG-3') and trnK 3'end primer (5'-GGGACTCGAACCCGGAA-3') (this study). Amplified product size was used to determine MatK splicing activity. Unspliced product would result in a band of $\sim 2833$ base pairs (bp) while spliced product would result in a band of 50 to 61 bp depending on species. PCR products were resolved on $1.7 \%$ agarose gels stained with Ethidium Bromide and visualized on a UV transluminator. PCR products indicative of matured $\operatorname{trnK}$ were gel excised and extraneous components removed using the QIAquick Gel Extraction kit (Qiagen) followed by sequencing to confirm identity.

\section{Availability of supporting data}

The data set used for phylogenetic analysis supporting results of this article is available in Dryad, DOI number: doi: 10.5061/dryad.j4489 [76].

\section{Additional files} Additional file 1: Table S1. Listing of all species and associated
accessions used in the phylogenetic analysis and evolution of the
alternative initiation codon. (PDF $316 \mathrm{~kb}$ )

Additional file 2: Figure S1. The nucleotide sequence alignment of the $5^{\prime}$ end of the matK open reading frame for 104 Orchidaceae and outgroup monocot taxa. Alignment was manually carried out in QuickAlign [66] with gaps being introduced at the cost of two or more substitutions. (a) The $5^{\prime}$ region of matk in all orchids with sequence extending beyond the conserved initation codon. (b) Alignment highlighting the use of the consensus (cic) vs. the alternative initiation codon (aic) in orchids and related outgroup species. Species that use the cic have a gap added to the extreme $5^{\prime}$ end of the matk sequence. The gray arrow indicates the aic while the black arrow indicates the cic. The special case of Neottia nidus-avis which produces a full-length matK ORF using the -6 in-frame initiation codon is highlighted in red. Outgroup monocots are indicated with a bracket. (PDF $264 \mathrm{~kb}$ )

Additional file 3: Figure S2. A RAxML phylogeny of over 100 taxa in the Orchidaceae based on matK open reading frame nucleotide sequences computed in the CIPRES portal (http://www.phylo.org) [70] applying the default settings and conducting 1000 replicates. The tree is rooted with members of the Asparagales (monocot) families Asteliaceae (Astelia alpina, Milligania stylosa), Blandfordiaceae (Blandfordia grandiflora), Boryaceae (Borya septentrionalis), Hypoxidaceae (Hypoxis hemerocallidea, Spiloxene serrate) and Lanariaceae (Lanaria lanata). Taxa names are abbreviated following the limits set in the programs for character number. A summary tree of this data is provided in the main manuscript as Fig. 6. (PDF 308 kb)

Additional file 4: Figure S3. Alignment of current accessions available for Phaius tancarvilleae in GenBank. Initiation codon required for full-length MatK translation is noted to the right of the alignment: aic = alternative initiation codon, $\mathrm{cic}=$ consensus initiation codon. Nucleotides are color coded: adenine = yellow; thymine = red; guanine = green; cytosine = blue. (PDF 92 kb)

Additional file 5: Table S2. Source of plant material used in molecular assays. (PDF $922 \mathrm{~kb}$ )

\section{Competing interests}

The authors declare that they have no competing interests. 


\section{Author contributions}

M.M.B. constructed and analysed alignments for Fig. 1 and Fig. 2, designed and performed molecular assays and wrote the manuscript. K.S. optimized and ran Western blots and splicing assays. K.W.H. initiated the study, performed phylogenetic analyses, co-wrote and edited manuscript. K.M. and J.P. downloaded the sequences for the large monocot data set, generated the alignments, conducted phylogenetic analyses, and contributed to the manuscript writing. All authors read and approved the final manuscript.

\section{Acknowledgments}

We thank John Siemon at Australian Botanic Garden, Mount Annan, NSW Australia for providing leaf tissue from native Australian orchids in collection for use in molecular assays, Fang-Ju Lin and Doug Van Hoewyk at Coastal Carolina University for lab space and equipment for assays, Scott Parker for editorial comments on the manuscript. We thank the two anonymous reviewers for their valuable comments and suggestions.

\section{Funding}

This project was funded from student research funds provided by the Department of Biology at Coastal Carolina University to M.M.B and NSF-USA EF-043105 to K.W

\section{Author details}

1Department of Biology, Coastal Carolina University, Conway, SC 29526, USA. ${ }^{2}$ School of Biological Sciences, University of Sydney, Sydney, NSW 2006, Australia. ${ }^{3}$ Department of Biological Sciences, Virginia Tech, Blacksburg, Virginia 24061, USA.

\section{Received: 14 July 2015 Accepted: 20 September 2015} Published online: 29 September 2015

\section{References}

1. Mohr G, Lambowitz AM. Putative proteins related to group II intron reverse transcriptase/maturases are encoded by nuclear genes in highter plants. Nuc Acids Res. 2003;31:647-52.

2. Zoschke R, Nakamura M, Liere K, Sugiura M, Börner T, Schmitz-Linneweber C. An organellar maturase associates with multiple group II introns. Natl Acad Sci U S A. 2010;107:3245-50.

3. Mohr G, Perlman PS, Lambowitz AM. Evolutionary relationships among group II intron-encoded proteins and identification of a conserved domain that may be related to maturase function. Nuc Acids Res. 1993;21:4991-7.

4. Cui X, Matsuura M, Wang Q, Ma H, Lambowitz AM. A group II intronencoded maturase functions preferentially in cis and requires both the reverse transcriptase and $X$ domains to promote RNA splicing. J Mol Biol. 2004;340:211-31.

5. Keren I, Bezawork-Geleta A, Kolton M, Maayan I, Belausov E, Levy M, et al. AtnMat2, a nuclear-encoded maturase required for splicing of group-\|I introns in Arabidopsis mitochondria. RNA. 2009;15:2299-311.

6. Sugita M, Shinozaki K, Sugiura M. Tobacco chloroplast tRNALys (UUU) gene contains a 2.5-kilobase-pair intron: an open reading frame and a conserved boundary sequence in the intron. Proc Natl Acad Sci U S A. 1985;82:3557-61.

7. Neuhaus H, Link G. The chloroplast tRNA ${ }^{\text {Lys }}$ (UUU) gene from mustard (Sinapsis alba) contains a class II intron potentially coding for a maturaserelated polypeptide. Curr Genet. 1987;11:251-7.

8. Hausner G, Olson R, Simon D, Johnson I, Sanders ER, Karol KG, et al. Origin and evolution of the chloroplast trnK (matK) intron: A model for evolution of group II intron RNA structures. Mol Biol Evol. 2006;23:380-91.

9. Duffy AM, Kelchner SA, Wolf PG. Conservation of selection on matK following an ancient loss of its flanking intron. Gene. 2009;438:17-25.

10. Ems SC, Morden CW, Dixon CK, Wolfe KH. dePamphilis CW, Palmer JD. Transcription, splicing and editing of plastid RNAs in the nonphotosynthetic plant Epifagus virginiana. Plant Mol Biol. 1995;29:721-33.

11. McNeal JR, Kuehl JV, Borre JL, Leebens-Mach J, DePamphilis CW. Parallel loss of plastid introns and their maturase in the genus Cuscuta. PLoS One. 2009:4:e5982.

12. Barthet MM, Hilu KW. Expression of matK: Funcitonal and evolutionary implications. Am J Bot. 2007:94(8):1402-12.

13. Hertel S, Zoschke R, Neumann L, Qu Y, Axmann IM, Schmitz-Linneweber C. Multiple checkpoints for the expression of the chloroplast-encoded splicing factor MatK. Plant Phys. 2013;163:1686-98.
14. Hess WR, Hoch B, Zelts P, Hübschmann T, Kössel H, Börner T. Inefficient rp/2 splicing in barley mutants with ribosome-deficient plastids. Plant Cell. 1994;6:1455-65.

15. Hübschmann T, Hess WR, Börner T. Impaired splicing of the rps 12 transcript in ribosome-deficient plastids. Plant Mol Biol. 1996;30:109-23.

16. Vogel J, Hubschmann T, Borner T, Hess WR. Splicing and intron-internal RNA editing of trnK-matK transcripts in barley plastids: support for MatK as an essential splicing factor. J Mol Biol. 1997;270:179-87.

17. Vogel J, Borner T, Hess W. Comparative analysis of splicing of the complete set of chloroplast group II introns in three higher plant mutants. Nuc Acids Res. 1999;27:3866-74

18. Hirao T, Watanabe A, Kurita M, Kondo T, Takata K. A frameshift mutation of the chloroplast matK coding region is associated with chlorophyll deficiency in teh Cryptomeria japonica virescent mutant Wogon-Sugi. Curr Genet. 2009;55:311-21.

19. Simpson MG. Plant Systematics. 2nd ed. New York: Academic Press; 2010.

20. Kores PJ, Weston PH, Molvray M, Chase MW. Phylogenetic relationships within the Diurideae (Orchidaceae): inferences from plastid matK DNA sequences. In: Wilson KL, Morrison DA, editors. Monocots: systematics and evolution. Collingwood, Victoria, Australia: CSIRO Publishing; 2000. p. 449-56.

21. Whitten WM, Williams NH, Chase MW. Subtribal and generic relationships of Maxillarieae (Orchidaceae) with emphasis on Stanhopeinae: combined molecular evidence. Am J Bot. 2000:87:1842-56.

22. Freudenstein JV, Senyo DM. Relationships and evolution of matK in a group of leafless orchids (Corallorhiza and Corallorhizinae; Orchidaceae: Epidendroideae). Am J Bot. 2008;95:498-505.

23. Kocyan A, Vogel EFD, Conti E, Gravendeel B. Molecular phylogeny of Aerides (Orchidaceae) based on nuclear and two plastid markers: A step forward in understanding the evolution of the Aeridinae. Mol Phylogenet Evol. 2008;48:422-43.

24. Harrison P, Zheng D, Zhang Z, Carriero N, Gerstein M. Transcribed processed pseudogenes in the human genome: an intermediate form of expressed retrosequence lacking protein-coding ability. Nuc Acids Res. 2005;33:2374-83.

25. Zheng D, Frankish A, Baertsch R, Kapranov P, Reymond A, Choo SW, et al. Pseudogenes in the ENCODE regions: Consensus annotation, analysis of transcription, and evolution. Genome Res. 2007;17:839-51.

26. Logacheva MD, Schelkunov MI, Penin AA. Sequencing and analysis of plastid genome in mycoheterotrophic orchid Neottia nidus-avis. Genome Biol Evol. 2011;3:1296-303.

27. Hilu KW, Liang $\mathrm{H}$. The matK gene: sequence variation and application in plant systematics. Am J Bot. 1997;84:830-9.

28. Young ND, De Pamphilis CW. Purifying selection detected in the plastid gene matK and flanking ribozyme regions within a group II intron of nonphotosynthetic plants. Mol Biol Evol. 2000;17:1933-41.

29. Hilu KW, Borsch T, Muller K, Soltis DE, Soltis PS, Savolainen V, et al. Angiosperm phylogeny based on matK sequence information. Am J Bot. 2003:90:1758-76.

30. Hilu KW, Black CM, Oza D. Impact of gene molecular evolution on phylogenetic reconstruction: A case study in the rosids (superorder Rosanae, angiosperms). PLoS One. 2014;9:e99725.

31. Lahaye R, Bank MVD, Bogarin D, Warner J, Pupulin F, Gigot G, et al. DNA barcoding the floras of biodiversity hotspots. Proc Natl Acad Sci U S A 2008;105(8):2923-8.

32. Hollingsworth PM, Forrest LL, Spouge $J$, Hajibabae M, Ratnasingham S, van der Bank M, et al. A DNA barcode for land plants. Proc Natl Acad Sci U S A. 2009;106:12794-7.

33. de Vere N, Rich TCG, Ford CR, Trinder SA, Long C, Moore CW, et al. DNA barcoding the native flowering plants and conifers of Wales. PLoS One. 2012;7:e37945.

34. Magallón S, Hilu KW, Quandt D. Land plant evolutionary timeline: gene effects are secondary to fossil constraints in relaxed clock estimation of age and substitution rates. Am J Bot. 2013;100:556-73.

35. Tang Y, Yukawa T, Bateman RM, Jiang H, Peng H. Phylogeny and classification of the East Asian Amitostigma alliance (Orchidaceae: Orchideae) based on six DNA markers. BMC Evol Biol. 2015;15:96. doi:10.1186/s12862-015-0376-3.

36. Barthet MM, Hilu KW. Evaluating evolutionary constraint on the rapidly evolving gene matK using protein composition. J Mol Evol. 2008;66:85-97.

37. Hirose T, Sugiura M. Functional Shine-Delgarno like sequences for translation initiation of chloroplast mRNAs. Plant Cell Phys. 2004;45:114-7.

38. Esposito D, Hicks AJ, Stern DB. A role for initiation codon context in chloroplast translation. Plant Cell. 2001;13:2373-84. 
39. Kores PJ, Molvray M, Weston PH, Hopper SD, Brown AP, Cameron KM, et al. A phylogenetic analysis of Diurideae (Orchidaceae) based on plastid DNA sequence data. Am J Bot. 2001;88:1903-14.

40. Salazar GA, Chase MW, Arenas S, Ingrouille M. Phylogenetics of Cranichideae with emphasis on Spiranthinae (Orchidaceae, Orchidoideae): evidence from plastid and nuclear DNA sequences. Am J Bot. 2003:90:777-95.

41. Salazar GA, Jost L. Quechua, a new monotypic genus of Andean Spiranthinae (Orchidaceae). Syst Bot. 2012;37:78-86.

42. Kocyan A, Qiu Y-L, Endress PK, Conti E. A phylogenetic analysis of Apostasioideae (Orchidaceae) based on ITS, trnL-F and matK sequences. Plant Syst Evol. 2004;247:203-13.

43. Dinesh-Kumar SP, Miller WA. Control of start codon choice on a plant viral RNA encoding overlapping genes. Plant Cell. 1993;5:679-92.

44. Kozak M. The scanning model for translation: An update. J Cell Biol. 1989;108:229-41.

45. Zoschke R, Ostersetzer O, Börner T, Schmitz-Linneweber $C$. Analysis of the regulation of MatK gene expression. Endocyt Cell Res. 2009;19:127-35.

46. Yang J-B, Tang M, Li H-T, Zhang Z-R, Li D-Z. Complete chloroplast genome of the genus Cymbidium: lights into the species identification, phylogenetic implications and population genetic analyses. BMC Evol Biol. 2013;13:84.

47. Pan C, Liao D-C, Wu F-H, Daniell H, Singh ND, Chang C, et al. Complete chloroplast genome sequence of an orchid model plant candidate: Erycina pusilla apply in tropical Oncidium breeding. PLoS One. 2012;7:e34738.

48. Wu F-H, Chan M-T, Liao D-C, Hsu C-T, Lee Y-W, Daniell H, et al. Complete chloroplast genome of Oncidium Gower Ramsey and evaluation of molecular markers for identification and breeding in Oncidiinae. BMC Plant Biol. 2010;10:68.

49. Chang C-C, Lin H-C, Lin I-P, Chow T-Y, Chen H-H, Chen W-H, et al. The chloroplast genome of Phalaenopsis aphrodite (Orchidaceae): Comparative analysis of evolutionary rate with that of grasses and its phylogenetic implications. Mol Biol Evol. 2006;23:279-91.

50. Jheng C-F, Chen T-C, Lin J-Y, Chen T-C, Wu W-L, Chang C-C. The comparative chloroplast genomic analysis of photosynthetic orchids and developing DNA markers to distinguish Phalaenopsis orchids. Plant Sci. 2012;190:62-73.

51. Delannoy E, Fujii S, Francs-Small CCD, Brundrett M, Small I. Rampant gene loss in the underground orchid Rhizanthella gardneri highlights evolutionary constraints on plastid genomes. Mol Biol Evol. 2011;28:2077-86.

52. Freudenstein J, Barrett CF, Yukawa T. Corallorhiza (Orchidaceae) has two copies of matK, one of which is a pseudogene. Botany \& Mycology 2009. Snowbird, Utah, USA: Botanical Society of America; 2009.

53. Miyata $T$, Hayashida $H$. Extraordinarily high evolutionary rate of pseudogenes: Evidence for the presence of selective pressure against changes between synonymous cod. Proc Natl Acad Sci U S A. 1981;78:5739-42

54. Tillich M, Schmitz-Linneweber C, Herrmann RG, Maier RM. The plastid chromosome of maize (Zea mays): Update of the complete sequence of the transcript editing sites. Maize Genet Coop News Lett. 2001;75:42-4.

55. Tillich M, Funk HT, Schmitz-Linneweber C, Poltnigg P, Sabater B, Martin M, et al. Editing of plastid RNA in Arabidopsis thaliana ecotypes. Plant J. 2005;43:708-15.

56. Tillich M, Sy VL, Schulerowitz K. Haeseler Av, Maier UG, Schmitz-Linneweber C. Loss of matK RNA editing in seed plant chloroplasts. BMC Evol Biol. 2009:9:201-11.

57. Luo J, Hou B-W, Niu Z-T, Liu W, Xue Q-Y, Ding X-Y. Comparative chloroplast genomes of photosynthetic orchids: Insights into eovlution of the Orchidaceae and development of molecular markers for phylogenetic applications. PLOS ONE. 2014;9:e99016. doi:10.1371.

58. Cameron KM, Chase MW, Whitten WM, Kores PJ, Jarrell DC, Albert VA, et al. A phylogenetic analysis of the Orchidaceae: Evidence from $r b c L$ nucleotide sequences. Am J Bot. 1999;86:208-24.

59. Stevens PF. Angiosperm Phylogeny Website, Version 12. http://www.mobot. org/MOBOT/research/APweb/. 2001 onwards.

60. Chase MW, Cameron KM, Barrett RL, Freudenstein JV. DNA data and Orchidaceae systematics: A new phylogenetic classification. In: Dixon KW, Kell SP, Barrett RL, Cribb PJ, editors. Orchid Conservation. Kota Kinabalu, Sabah: Natural History Publications; 2003. p. 69-89.

61. Burns-Balogh P, Funk VA. A phylogenetic analysis of the Orchidaceae. Smithsonian Contrib Bot. 1986;61:1-79.
62. Xiang X-G, Li D-Z, Jin W-T, Zhou H-L, Li J-W, Jin X-H. Phylogenetic placement of the enigmatic orchid genera Thaia and Tangtsinia: evidence from molecular and morphological characters. Taxon. 2012;61:45-54.

63. Freudenstein JV, Chase MW. Phylogenetic relationships in Epidendroideae (Orchidaceae), one of the great flowering plant radiations: progressive specialization and diversification. Ann Bot. 2015;115:665-81.

64. Hao DC, Mu J, Chen SL, Xiao PG. Physiochemical evolution and positive selection of the gymnosperm matK proteins. J Genet. 2010;89:81-9.

65. Hilu KW, Alice LA. Evolutionary implications of matK indels in Poaceae. Am J Bot. 1999:86:1735-41.

66. Müller J, Müller K. QuickAlign: A new alignment editor. Plant Mol Biol Rep. 2003;21:5.

67. Maddison WP, Maddison DR. Interactive analysis of phylogeny and character evolution using the computer program MacClade. Folia Primatol (Basel). 1989:53:190-202.

68. Kelchner SA. The evolution of non-coding chloroplast DNA and its application in plant systematics. Ann Missiouri Bot Gard. 2000;87:482-98.

69. Stamatakis A. RAxML Version 8: A tool for phylogenetic analysis and post-analysis of large phylogenies. Bioinformatics. 2014;10:1093/bioinformatics/btu033.

70. Miller MA, Pfeiffer W, Schwartz T, editors. Creating the CIPRES Science Gateway for inference of large phylogenetic trees. Proceedings of the Gateway Computing Environments Workshop (GCE); 201014 November 2010; New Orleans.

71. Rambaut A: FigTree Ver. 1.3.1. Http://tree.bio.ed.ac.uk/software/figtree/. 2009.

72. Accelrys Software Inc. Discovery Studio Modeling Environment, Release 4.0. San Diego: Accelyrs Software Inc; 2013.

73. Doyle JJ, Doyle JL. Isolation of plant DNA from fresh tissue. Focus. 1990;12:13-25.

74. Hilu KW, Black C, Diouf D, Burleigh G. Phylogenetic signal in matK vs. trnK: A case study in early-diverging eudicots (Angiosperms). Mol Phylogenet Evol. 2008:48:1120-30.

75. Jones CG, Hare JD, Compton SJ. Measuring plant protein with the Bradford assay. J Chem Ecol. 1989;15:1979-92.

76. Barthet MM, Moukarzel K, Smith KN, Patel, J, Hilu KW. Nucleotide alignment supporting phylogeny. Dryad repository. 2015. doi: 10.5061/dryad.j4489.

\section{Submit your next manuscript to BioMed Central and take full advantage of:}

- Convenient online submission

- Thorough peer review

- No space constraints or color figure charges

- Immediate publication on acceptance

- Inclusion in PubMed, CAS, Scopus and Google Scholar

- Research which is freely available for redistribution 